\title{
Students, earthquakes, media: does a seismic crisis make a difference?
}

\author{
GEMMA MUSACCHIO*, STEFANO SOlARINO**, ElENA \\ EVA**AND GIOVANNA L. PIANGIAMORE*** \\ * Istituto Nazionale di Geofisica e Vulcanologia, AC, Roma; \\ gemma.musacchio@ingv.it \\ ** Istituto Nazionale di Geofisica e Vulcanologia, CNT, Sede di \\ Genova, Genova \\ ***Istituto Nazionale di Geofisica e Vulcanologia, Roma 2, Sede \\ di Portovenere, Fezzano di Portovenere (SP)
}

\begin{abstract}
How do students use the big data flow of information from the Internet? What is their opinion and trust in scientists? To what extent catastrophic earthquakes and environmental disasters influence their opinion? In this study we present the results of a poll conducted on high school students (age 13-20) to assess young Italian citizens' trust on geoscientists and their science. The sample of about 700 students refers to areas prone to natural hazards ranging from low to moderate intensity. To allow a fast and easy compilation, held directly in school, the poll included only a very few questions. They investigated and accessed the source where the students retrieve information on catastrophes and natural phenomena, the role of scientists in everyday life and scientists' ethical integrity.

Although limited, this is the first poll of this kind and data collected up to now can be used for a rough picture of the present situation, to compare results with recent disasters and to project future results of on-going analysis. All information will also help us in a future analysis to understand if and to what extent a recent earthquake or environmental local crisis can affect the perception.

Students do not completely trust that scientists are genuinely independent from outer urges. They also believe that media manipulate information with willful misconduct, to hide inconvenient realities or to get economic advantages. However answers from our Emilia sample of students were unexpected: they did not show any specific bias after the 2012 seismic sequence. Conversely they show less skepticism towards scientists and scientific integrity in comparison to students from other regions. This suggests that the perception towards science and scientists might be driven by cultural and social background and not necessarily affected by recent seismic crisis. In this perspective this on-going study will be challenged as soon as poll after the Amatrice 2016 seismic sequence will be available.
\end{abstract}




\section{INTRODUCTION}

$\mathrm{R}$ an unprecedented, yet unexpected, level of citizens scientific literacy: only $13 \%$ of interviews gave fully wrong answers to basic science questions (Pellegrini and Saracino, 2016). As citizens' age increases their knowledge in science does the opposite, making young students an interesting mirror of what would be the future society of science and technology.

Youths are also known as capable of strong criticism towards society: they watch and are judgmental towards actions that have brought to any present situation. They profit from scientific outcome in technology; they watch, with wide-open eyes, risks posed by disregard towards environment, misusage of resources, and wrong application of building codes. They judge societal efforts towards risk mitigation. In a land prone to earthquake hazard, youth may represent the key resource towards risk mitigation.

Opinion, knowledge and understanding are not mostly built at school. Youths are native digital; they surf Internet and live in Social Media, in a world where information seem not to have time or space limits anymore. A few hours after the Amatrice Mw 6.0 earthquake twitter had reached more than half a million of posts (Musacchio and Piangiamore, 2016).

As speed and wealth of information increase, quality might not follow the same pattern and final users are not always aware of sources reliability. On the other hand, science suffers of intrinsic uncertainty and knowledge often raises more enquires than expected. In this frame alternative hypotheses, not necessarily based on solid scientific ground, might find their way out on the web. Furthermore, scientists still underestimate the opportunity the web offers to spread knowledge and increase public understanding of science.

How are the young citizens dealing with the unprecedented flow of information provided by Internet? What is their opinion and trust in scientists? How far is this affected by the occurrence of a seismic crisis?

Here we try to answer to some of the above questions investigating on the sources of information on Earth Science on which high school students (aged 13 to 20 years) rely. The work is unique, as none of the published poll dealing with the impact of science in layman's opinion specifically address geoscience and/or students.

\section{DATA}

The data analyzed in this study are the responses of Italian students to a questionnaire mainly aiming at 1) knowing what sources they use to get informed and updated about natural disasters 2) estimating their level of trust in earth scientists and their science 3) getting their opinion about whether scientists are biased by external pressures (money, politics, career, governmental institutions, media) 4) understanding if and how much a recent earthquake can affect their opinion, in the perspective to compare the results of such analysis with the Amatrice case.

The questionnaire was made available on the Internet to schools by direct contact with teachers. To avoid vandalism, the questionnaire was mainly compiled during school 
time and a password was provided to each teacher in order to identify fake answers. Particular care has been taken that the respondents were not aware of which institution was in charge of the research study to avoid preconceptions in the results. A series of automated scripts were designed to quickly update the statistics of the answers in near real time.

The ideal sample would have been data from each one of the Italian regions, but this would have required a longer time for collec- tion. In order to get prompt results to be used for reference after the Amatrice 2016 earthquake we perform our analysis on the available sample, which will be possibly increased in the next future. The data cover almost all Northern Italy, while only few questionnaires were filled in the Central and Southern Italian peninsula (red circles in Fig. 1). In particular, data from the Emilia region, recently hit by a major earthquake in 2012 (yellow star in Fig. 1) allowed to approach with point 4 of our study.
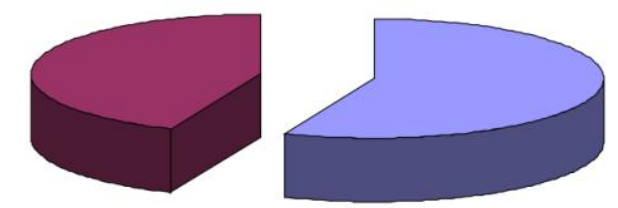

Female

Male

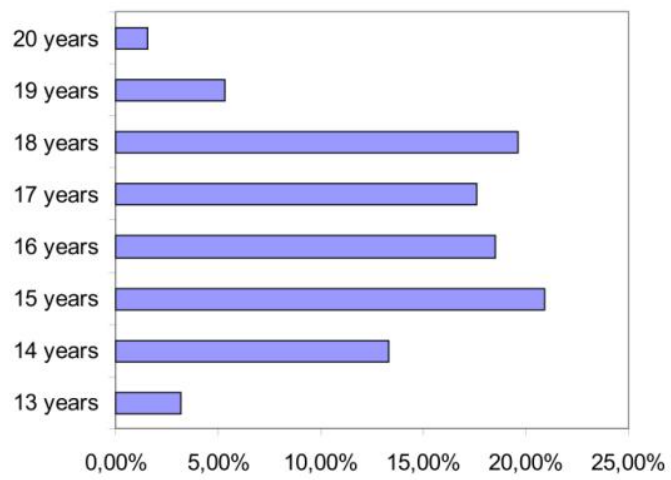

Figure 1. Left panel. Regions where data were collected. Most questionnaires were filled in Northern Italy. The stars are the location of the most recent, destructive earthquakes in Italy. Right panels. Top, distribution of the sample with sex. Bottom, age of the respondents.

We collected more than 720 questionnaires; after a quality selection to remove unreliable and fake answers, they were reduced to 698 .
The English version of the questionnaire is available at the web address: 
https://docs.google.com/forms/d/e/1FAIp QLSeVp7zbuToLT5RFUB_pRyWRLzTB1ksN6G_DTnyf2fsM3sFtg/viewfo $\underline{\mathrm{rm}}$

There are four main blocks: the personal data block, the sources block, the scientists in society block and the ethical block.

The personal data block allowed to collect information on the age, the region they live, the type of school. In the Italian educational system school is compulsory till age 16 . There are three levels of high schools for the age 13 to 20 (right - bottom panel in Fig. 1) having different targets: the Istituto Professionale is mainly devoted to form citizens who want to be hired by companies in the tertiary sector or as independent crafts. The Istituto Tecnico is chosen by students who want to get a career as professionals in many fields or be hired under higher responsibilities positions. Although all schools allow to attend the University, the Liceo is usually the one having vocation for higher education.

The sources block aims at knowing what sources students use to get information on natural phenomena and whether they attend scientific conferences and talks. The question about sources breaks down into several items, including Internet and social networks (Fig. 2). This distinction allows to have a first feedback on the reliability of the source. As a matter of fact, one can assess the accountability of websites while social networks are platforms more prone to manipulation. On Social networks identity and skills of information providers are often not known (Solarino 2014 a, b) and information is seldom based on a primary source.

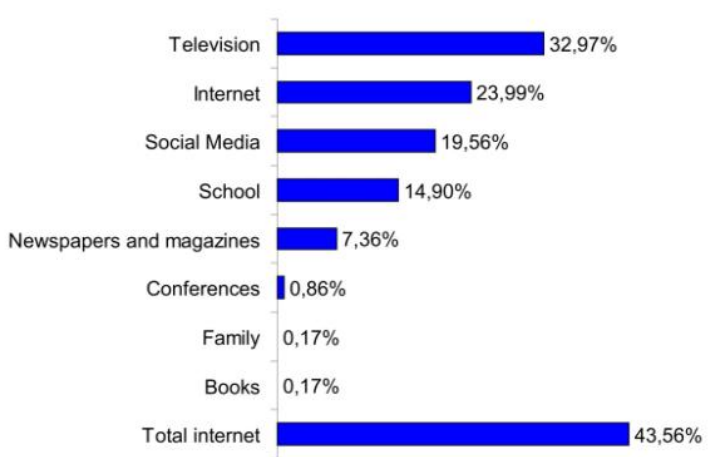

Figure 2. Sources of information. Students could choose up to three answers.

The scientists in society block aims at estimating the role of scientists in everyday life, by checking if students believe that scientists can really help society to improve and how clear and reliable they are.

Finally, the last block wants to test the "ethical integrity" of scientists with a couple of questions about the external pressure that scientists might have. The last question is about the manipulation of news and information by the media; in case of a positive answer the questionnaire also provides a list of possible explanations that can be chosen by the respondents.

We let some room for intermediate answers by giving five choices for each questions (not at all, a little, fairly, much, very much). To interpret the answers, we decided that the first two scores are negative (not at all and a little equals no), the rest positive.

The length of the questionnaire is designed as a good compromise between the attention limits and curiosity that students might have. Moreover, since many classes filled in the questionnaire during regular lessons, we 
wanted to avoid that in case of subsequent compilation (for example for schools where the number of available computers is much less than the number of potential respondents) the students loose too much school time. The average time for the completion of the questionnaire proved to be of about $1 \mathrm{~m}$ $30 \mathrm{sec}$.

\section{RESULTS}

Our sample was made of about $56 \%$ and $44 \%$ male and female students respectively (right - top panel of Fig. 1). The two extreme ages, 13 and 20, only represent about 3 and $1.5 \%$; the intermediate ages are all well balanced (right - bottom panel, Fig. 1). It is especially noteworthy that 15 and 18 -beginning and end of high school- are well represented and reach $20 \%$ each. It is interesting to check if and how the schooling or the age changes the students' minds by comparing the answers from these two peculiar ages.

Most of our respondents (about 78\%) are Liceo students while Istituto Tecnico and Professionale are represented only by $17 \%$ and 5 $\%$ of the sample, respectively.

Let's first analyze the answers from a general point of view, beginning from the source of information. The percentage that we computed here is somewhat different from the rest because the respondents in this case are allowed to provide multiple answers, up to three. The estimate is thus calculated from the total number of answers, but it is not directly linked to the sample as any respondent may have answered one to three times. Only very few students attended a scientific conference recently, while the majority (57\%) never did. However, an overall $43 \%$ at- tended at least once. As expected, conferences, together with books and family, are not the main sources of information about natural phenomena. A fair amount of respondents gets this kind of information from school as about $15 \%$ of the answers pointed out that school is a source; we argue that the students' answers meant the scientific part of the phenomena rather than the societal aspects. This percentage is pretty high, but if we consider that it is a value computed on the answers and not on the number of respondents, we can highlight that school may indeed not be the only source. We thus conclude that students are being informed by non-authoritative sources, since Internet, social media and TV make up to $78 \%$ of their informants. In particular, if taken as a single (Internet or social media), none of the two "digital" sources gave higher results than $\mathrm{TV}$, which is still the primary way to get informed about natural disasters among young people (Fig. 2).

We also underline that the gradual decline of newspapers and magazines as sources of scientific information (they account for less than $8 \%$ ) is accompanied, as a cause or a consequence, by the dramatic reduction of the scientific journalists (Bauer et al., 2013) and by the proliferation of online scientific authors, often inexperienced or amateur, that simply make "cut and paste" job, flooding the web of rumors (Davies, 2008; Foresta Martin and Peppoloni, 2015). This opens a debate on the quality and reliability of information, which will be discussed later on.

In regards to the role of scientists in society, the majority of the students believe that scientists are reliable and their studies are 
useful (about 76\%); an encouraging $80 \%$ believe that scientists are clear in explaining their studies, and the relative results and only less than $20 \%$ of the sample thinks that the research does not help the society to face natural disasters. However about $56 \%$ of the students believe that the research is biased by politics and the industry, and a similar amount believes that scientists do not disseminate important discoveries or results to accomplish other people or personal interest.

Finally, the last part of the questionnaire reveals that more than $80 \%$ of the students believe that the media are manipulating the information. It must be remarked that studies related to "responsible behavior" of journalists on the whole European Community (Eurobarometer) provide for Italy a slightly different result: according to this study some $54 \%$ of the Italians thinks that journalists behave responsibly, compared to $80 \%$ of our respondents believe the opposite thing. Moreover, a significant $42 \%$ of the positive answers of our study attribute this behavior to the need of hiding "troublesome" realities. In descending order, $34 \%$ attribute the issue to economic interest, $18 \%$ to the explanation that false news are more appealing to the society while only $5 \%$ believe that journalists and entertainers are not expert. In practice, this view shares the general belief of a "conspiracy" (Solarino, 2015) of the media while attributing skills and competence to journalists. This means that our students do not believe to news simply because they think that the provider is cheating, not because it is not a professional on the field. The belief of a "conspiracy" grows for students with age. The trend is very clear that from 14 to 19 years old our respondents believe more (with an increase of $5 \%$ on average per year) that scientists depend on non-scientific institutions and rise their tendency to hide important results for personal interests.

\section{DISCUSSION AND CONCLUSIONS}

We now make an analysis by decomposing the results according to the sex, age and location of the respondents to see if there is any particular trend. As already discussed, the sample is limited in number of entries and geographical distribution compared to the whole nation, but since there exists no similar analysis on the topic yet, it is worth doing it.

For what concerns sex, it must be remarked that the two samples male and female differ of about 90 units, the first being more represented. Results must be considered in relative percentage. In general female have more trust than male students on scientists and on their studies; they also believe that researchers behave correctly and are not being biased by personal or economic interests. Instead results are very similar for what concerns manipulation: male and female share, with almost identical percentages, the idea that media are manipulating information. We can finally analyze the results with respect to the geography with the aim to understand if a recent earthquake has an im-pact on the opinion of the students towards our questions. In particular, we compare the answers of the students from the Emilia region, where the two major shocks of a seismic sequence caused 27 casualties in May 2012, with those in regions where seismic events have not recently occurred. The results may be a reference for further studies 


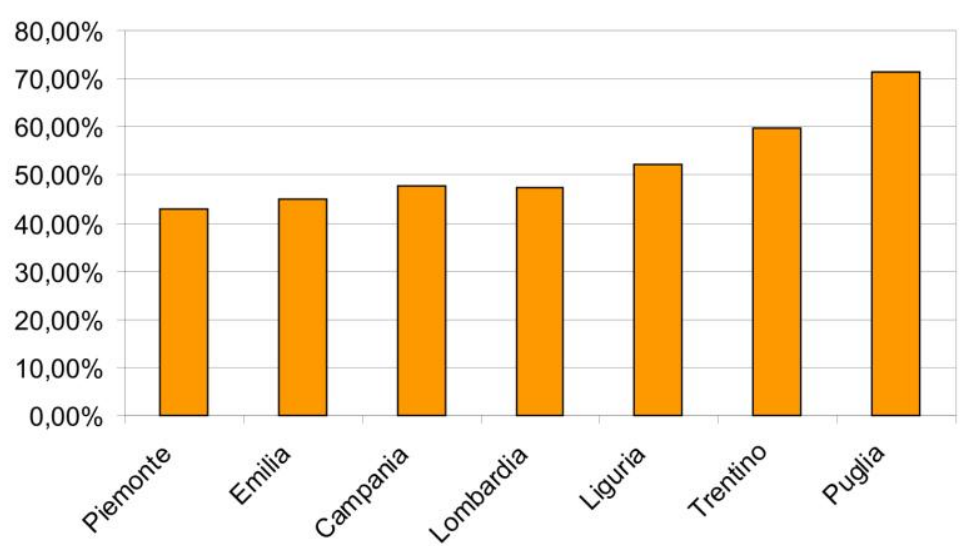

Do you think that the scientists depend on the interests of politics, economics or industry?

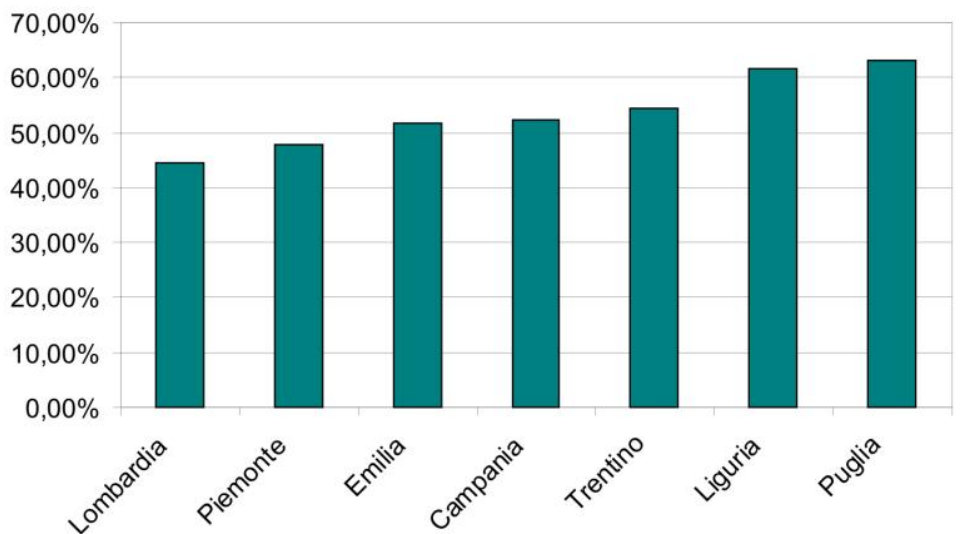

\section{Do you believe that} scientists may not disseminate scientific results to get personal gain or to cover someone else' interests?

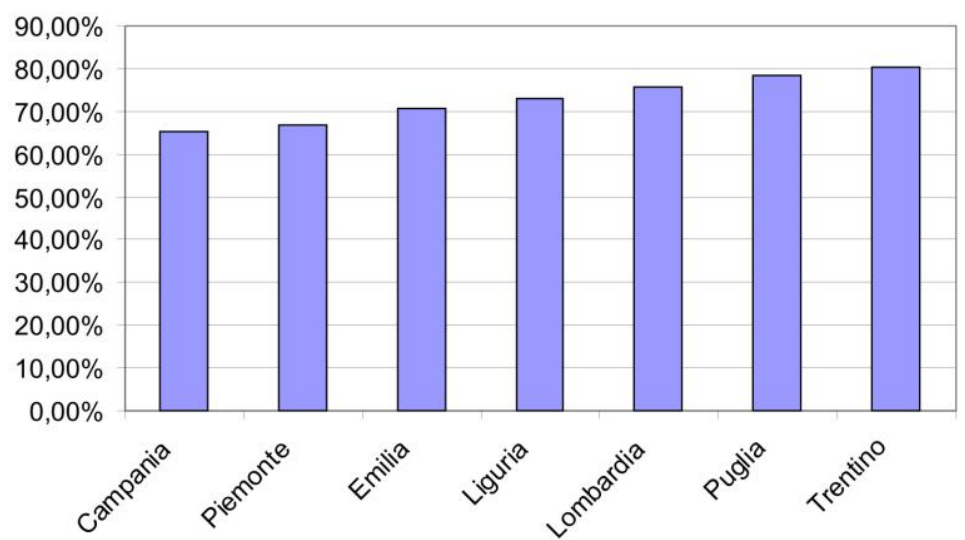

Do you believe that the media falsify or counterfeit news?

Figure 3. Comparison of the answers (top to bottom) relative to the integrity (dependence of scientists from outer urges) of scientists, their tendency to hide information to the society and the manipulation of information from the media. The Emilia is among the regions in which students have most trust in scientists. 
that will be done in the regions shaken recently by the Amatrice earthquake (August 2016). Fig. 3 reports such a comparison for some of the questions. From top to bottom of figure 3, the histograms display the answers on the dependence of the scientists from outer factors, their tendency to hide information to get personal gain or to favor other people and the manipulation of news by the media.

In the three cases the respondents do not seem to be biased by the occurrence of the earthquake, since the answers from the Emilia students are very similar to other regions where a seismic event has not recently happened. Even more, by comparing our results with the trend of the whole country as published in the Euro-barometer (TNS Opinion \& Social, 2013), it looks like the regions on the left part of the histograms are aligned with the opinion of the country, while those on the right part, which are regions from both North and South of the country, disagree strongly with the rest of the Italian citizens on these topics.

Unfortunately we do not have information about the opinion of the Emilia students before the earthquake, so we can only propose that the occurrence of an earthquake possibly does not decrease trust in scientists but, conversely, probably decreases the belief that scientists and journalists do no behave in an ethical way.

\section{ACKNOWLEDGEMENTS}

This work profited from the participation of students and teachers of the following schools:
Istituto Statale d'Istruzione Superiore "J. M. Keynes", Gazzada (VA) (www.iisskeynes.it); Liceo Scientifico "L. Cremona", Milano (http://www.iiscremona.gov.it/); Istituto Superiore "E. Fermi", Arona (NO) (http://www.iisenricofermiarona.it/);

Licei ed Istituti Tecnici del "Polo Scolastico Superiore della val Tidone", Castel San Giovanni, Borgonovo Val Tidone (PC) (http://www.polovoltacasali.gov.it/);

Liceo Artistico "Ciardo-Pellegrino", Lecce (http://www.liceociardopellegrinolecce.govit/);

Liceo Scientifico "V. Sereni", Luino (VA) (http://liceoluino.gov.it/);

Istituto Statale distruzione Superiore, "A. Torrente", Casoria, Napoli (http://www.itctorrente.it/);

Liceo Scientifico "E. Torricelli", Bolzano (http://www.torricelli.bz.it/);

Istituto Tecnico "E Stein", Gavirate (VA) (http://www.istitutosup-gavirate.net/);

Liceo Scientifico "Istituto Champagnat", Genova (http://www.maristi.it/champagnat/liceo/);

Liceo Scientifico "Pacinotti" La Spezia (http://www.liceopacinotti.gov.it/);

Liceo Scientifico "Pacinotti" Levanto (SP)

(http://www.liceopacinotti.gov.it/);

Istituto Alberghiero "G. Casini" La Spezia (http://www.alberghierolaspezia.gov.it/).

We are grateful for their help.

The manuscript also profited from the comment and suggestions of an anonymous reviewer to whom we are very much indebted.

\section{REFERENCES}

[Bauer et al., 2013] Bauer, M. W., S. Howard, Y.J. Romo Ramos, L. Massarani and L. Amorim (2013). Global science journalism report: working conditions \& practices, professional ethos and future expectations. SciDev.Net, 
Trident Printers, UK. ISBN 978-1-909528-024.

[Davies, 2008] Davies, N. (2008). Flat Earth News: An Award-Winning Reporter Exposes Falsehood, Distortion and Propaganda in the Global Media. Chatto and Windus, London. ISBN-10: 0701181451.

[Foresta Martin and Peppoloni, 2015] Foresta Martin, F. and S. Peppoloni (2015). Geoethics in communication of science: the relationship between media and geoscientists. Poster. EGU General Assembly 2015, Vienna, Austria. id.4098

[Musacchio and Piangiamore, 2016] Musacchio, G. and L. G. Piangiamore (2016). The 2016 Amatrice seismic sequence in the Media. Annals of Geophysics, 59, Fast Track 5, 2016; DOI: 10.4401/ag-7263

[Pellegrini and Saracino, 2016] Pellegrini, G. and B. Saracino, (2016) Annuario Scienza Tecnologia e Società, il Mulino, 192.

[Solarino, 2014a] Solarino, S. (2014). Geoethics and Communications 1. Scientists, Politicians, Journalists, Media Entertainers, Sociologists. Can Ethics help to establish their exact role in communicating Geoscience ? G. Lollino et al (eds). Engineering Geology for Society and Territory. Vol. 7, 55-58.

[Solarino, 2014b] Solarino, S. (2014). Geoethics and Communications 2. Ethics, the notably absent from the Internet. G. Lollino et al (eds). Engineering Geology for Society and Territory. Vol. 7, 39-43.
[Solarino, 2015] Solarino S. (2015). How to strengthen public trust in geosciences. Peppoloni S. and Di Capua G. (eds). Geoethics: the role and responsibility of geoscientists. Geological Society, London, Special publications. 419, 117-124

[TNS Opinion \& Social, 2013] TNS Opinion \& Social. (2013). Special Eurobarometer 401. Responsible Research and Innovation (RRI), Science and Technology, 153. 